\title{
INCIDENCE OF THE THIRD AND FOURTH HEAD OF THE BICEPS BRACHII MUSCLE IN CAUCASIAN RACE - A STUDY AND REVIEW OF LITERATURE
}

\author{
Sushil Kumar *, Ritwik Baidya.
}

Assistant Professor, Anatomy division, Department of radiology, Weill Cornell, Medicine, New York.

\section{ABSTRACT}

Anatomic variations in the heads of biceps brachii are not uncommon. It varies from one head to seven heads but two heads (long and short) are considered normal. In this study, 56 arms from 28 cadavers were studied for third and fourth heads in the anatomy laboratory of Weill Cornell Medicine. We observed supernumerary heads in 5 cadavers $(8.92 \%)$, out of which three heads were seen in 4 cadavers $(7.14 \%)$ and four heads in only one cadaver $(1.78 \%)$. Clinically, these kinds of anomalies are important because supernumerary heads could compress neighboring blood vessels and nerves.

KEY WORDS: Accessory Heads, Biceps Brachii, Muscles, Variation.

Address for Correspondence: Dr. Sushil Kumar, Assistant Professor, Anatomy division, Department of radiology, Weill Cornell Medicine, New York. E-Mail: sushilbhu2001@yahoo.co.in

Access this Article online

Quick Response code

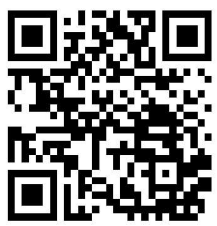

DOI: $10.16965 /$ ijar.2017.485
Journal Information

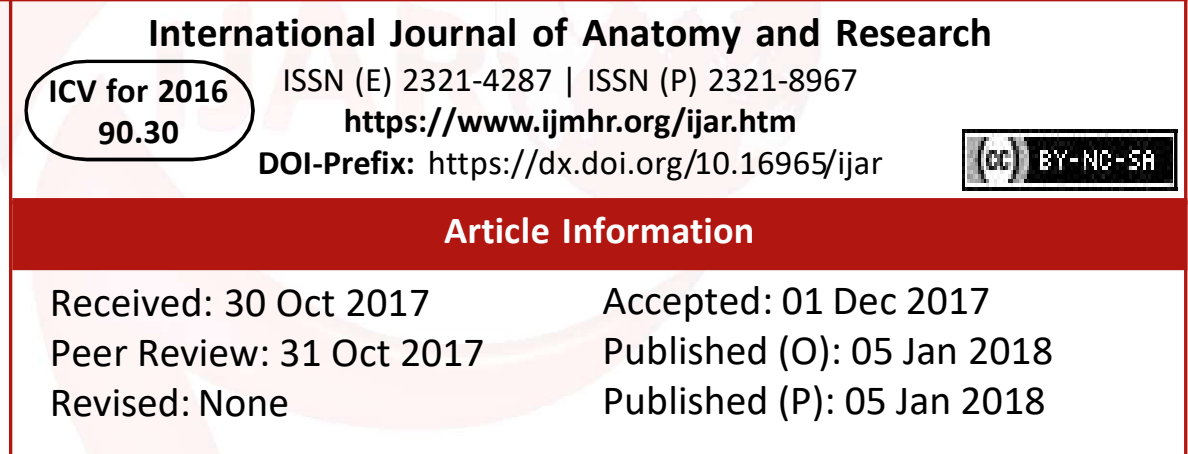

upper limb with the most frequent anatomic variations $[3,4]$. Incidence varies in different races [4]. The aim of this study was to assess the incidence of the third and fourth head of the biceps brachii muscle in Caucasian cadavers in the united states and compare it with other ethnic groups.

\section{MATERIALS AND METHODS}

28 dissected cadavers, 12 males and 16 females were used for this study. Fifty-six upper limbs (28 right and 28 left) were observed for additional heads of the biceps brachii muscle on already dissected cadavers at the Anatomy laboratory of Weill Cornell Medicine. Incidences of classical as well as additional heads were noted. Appropriate photographs were taken.

\section{RESULTS}

Among the 56 upper extremities studied, one 
male and one female cadaver had third head bilaterally. In one male cadaver four heads of biceps brachii was seen on the right side. The third head of the biceps brachii in all cases was arising from the anteromedial aspect of the lower part of the humeral shaft between the insertion of the coracobrachialis muscle and the origin of brachialis muscle. It inserted in the belly of the short head of the biceps brachii from the inferomedial aspect. The fourth head was present in one of the male cadaver. It was arising from the medial aspect of the greater tubercle of the humerus and blended with the long head of the biceps brachii from lateral side. Both the third and fourth heads of the biceps brachii were much slender and shorter than the other two heads. The nerve supplies of these two heads were also from the musculocutaneous nerve just like short head and long head.

Table 1: Showing incidence of supernumerary heads.

\begin{tabular}{|c|c|c|c|c|}
\hline No of heads & $\begin{array}{c}\text { No of cases } \\
(\mathrm{n}=\mathbf{5 6})\end{array}$ & $\begin{array}{c}\text { Percentage of } \\
\text { incidences }\end{array}$ & $\begin{array}{c}\text { Right arm } \\
(\mathrm{n}=\mathbf{2 8})\end{array}$ & $\begin{array}{c}\text { Left arm } \\
(\mathrm{n}=\mathbf{2 8})\end{array}$ \\
\hline 2 head & 51 & & 25 & 26 \\
\hline 3 head & 4 & & 2 & 2 \\
\hline 4 head & 1 & & 1 & - \\
\hline
\end{tabular}

Fig. 1: Showing $3^{\text {rd }}$ head of the biceps brachii muscle.

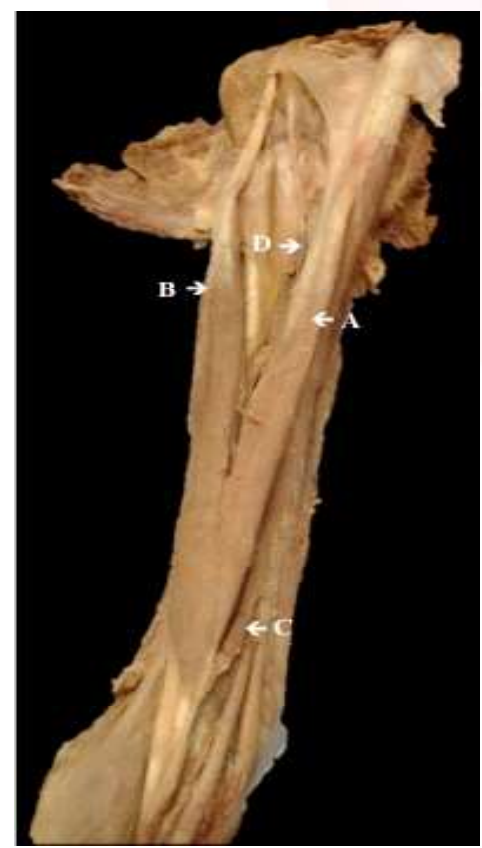
A - Short head of the bicep brachii
B - Long head of the bicep brachii
C - Third head of the bicep brachii
D- Fourth head of the bicep brachii

\section{DISCUSSION}

The biceps brachii muscle typically has two heads - long head that originates from the supraglenoid tubercle and a short head, which originates from the coracoid process of the scapula. Sometimes the supernumerary head is found as a third head or rarely fourth head. Heads up to seven has also been reported [3]. There is geographic and gender variations in the incidence of supernumerary heads. Gray's anatomy reported the incidence of the third head in $10 \%$ of cases [5]. Biceps brachii with three heads is found in $8 \%$ of Chinese, $10 \%$ of white Europeans, $18 \%$ of Japanese, $20.5 \%$ of South African blacks, $8.3 \%$ of South African white, $15 \%$ of Turkish and $37.5 \%$ of Colombians [6-12]. Incidence of variations on biceps brachii is more in males compare to females $[4,9,13,14]$.

However, there is no specific functional explanation for these findings in terms of geographic or gender differences [4]. Incidences of four heads are rare. Nakatani etal in 1998 reported this anomaly bilaterally. [15] Vazquez et al. in 2003 reported it unilaterally [16]. In 2008, Soubhgya et al reported one rare variation in which there was $4^{\text {th }}$ head in both biceps and triceps brachii muscle [17].

In our study, we observed 5 limbs out of 56 limbs $(8.92 \%)$ having supernumerary heads. Out of these we found three heads in 4 limbs (7.14\%) and $4^{\text {th }}$ head in one limb (1.78\%). Third head was present bilaterally in one male and one female cadaver. $4^{\text {th }}$ head was present in male cadaver on the right side. Left limb of this cadaver had normal two heads. In my study, incidence of supernumerary head is very close to the observation made by Aswat in South African white population [4]. Origins of the supernumerary heads are variable. According to the Gray's anatomy, third head arises from the superomedial part of the brachialis and is attached to the bicipital aponerosis and the medial side of the tendon of insertion [5].

According to Kosugi there are various sources of the origins of the additional heads, which are from humerus, medial intermuscular septum, tendon of pectoralis major or the deltoid and even from articular capsule or from the crest of the greater tubercle [10]. Kumar et al reported the presence of third head in $3.33 \%$ cases bilaterally [11]. In our study we also observed the bilateral presence of the third head. Kopuz et al 

AND REVIEW OF LITERATURE.

reported the origin of third head from the anterior surface of the humerus just distal to the insertion of coracocobrachialis just like our study [12]. Nakatani et al reported origin of $4^{\text {th }}$ head from the crest of the greater tubercle of the humerus. In our study we also found fourth head coming from the crest of the greater tubercle of the humerus. Developmentally third head is considered as detached part of the brachialis muscle [3]. Morphologically, third head is considered as the long head of coracobrachialis as it commonly originates from the point of insertion of coracobrachialis [4].

\section{CONCLUSION}

The presence of additional heads of the biceps brachii may confuse surgeons during surgery or radiologist while interpreting radiographs of the arm. Additional heads may compress the underlying nerves and produce symptoms of nerve compression or they may compress the underlying blood vessels and compromise the blood supply of the forearm and hand.

\section{Conflicts of Interests: None}

\section{REFERENCES}

[1]. Standring S. Gray's anatomy: The Anatomical Basis Of Clinical Practice. $41^{\text {st }}$ edition, London: Elsevier Ltd; 2016. p 824.

[2]. Sinnatamby C, Last's Anatomy: Regional and Applied. $12^{\text {th }}$ edition. Edinburg: Elsevier Churchill Livingstone, 2011; p103.

[3]. Testut L, Latarjet A. En: tratado de Anatomia Humana. Barcelona: Salvat, 1902.

[4]. Aswat R, Candler P, Sarmiento EE. High incidence of third head of biceps brachii in South African population. J Anat 1993;182:101-4.

[5]. Standring S. Gray's anatomy: The Anatomical Basis Of Clinical Practice. $40^{\text {th }}$ edition, London: Elsevier Ltd; 2008. p 825-26.
[6]. Shaw MA, Shaw M. Quadricipital M. Biceps brachii. J Anat.1986;80:54.

[7]. Higashi N, Sone C. A case of brachial biceps with two (right) and four (left) accessory heads bilaterally (in Japanese). J Kanazawa Med Uni 11:309-314.

[8]. Tountas CP, Bergman RA. Anatomic variations of the upper extremity. New York: Churchill Livingstone. 1993:97-9.

[9]. Bergman RA, Thompson SA, Afifi AK, Saadeh FA. Compendium of human anatomic variation. $1^{\text {st }}$ ed. Baltimore:Urban and Schwarzenberg. 1988:11.

[10]. Kosugi K, Shibata S, Yamashita H. Supernumerary humeral heads of the biceps brachii and branching pattern of the musculcutaneous nerve in Japanese. Surg Radiol Anat. 1992;14:175-85.

[11]. Kumar H, Das S, Rath G. An anatomical insight into the third head of biceps brachii muscle. Bratisl Lek Listy. 2008;100:76-8.

[12]. Kopuz C, Sancak B, Ozbenli s. on the incidence of third head of biceps brachii in Turkish neonates and adults. Kaibogaku Zasshi. 1999;74:301-5.

[13]. Rincon F, Rodriquez IZ, Sancez A. The anatomic characteristics of the third head of the biceps brachii muscle in Colombian population. Rev Chil Anat. 2002;20: 197-200.

[14]. Ilayperuma I, Nanayakkara G, Palahepitiya N. Incidence of humeral head of biceps brachii muscle Anatomical insight. Int. J. Morphol 2011;29:221225.

[15]. Nakatani T, Tanaka S, Mizukami S. Bilateral four headed biceps brachii muscles: the median nerve and brachial artery passing through a tunnel formed by a muscle slip from the accessory head. Clinical anatomy. 1998;11:209-12.

[16]. Vazquez T, Rodriguez-Niedenfuhr M, Oarkin I and Sanudo JR. A rare case of a four headed biceps brachii muscle with a double piercing by the musculocutaneous nerve. Surgical and radiological anatomy. 2003;25:5-6.

[17]. Nayak Soubhagya R, Krishnamurthy Ashwin, S J Kumar Madhan, V. Prabhu Latha, Saralaya Vasudha and $\mathrm{M}$ Thomas Merin. Four headed biceps and triceps brachii muscle with neurovascular variation. Anat sci International. 2008;83:107-111.

How to cite this article:

Sushil Kumar, Ritwik Baidya. INCIDENCE OF THE THIRD AND FOURTH HEAD OF THE BICEPS BRACHII MUSCLE IN CAUCASIAN RACE - A STUDY AND REVIEW OF LITERATURE. Int J Anat Res 2018;6(1.1):4854-4856. DOI: 10.16965/ijar.2017.485 